\title{
CIDADES CAMINHÁVEIS: AS INFLUÊNCIAS DO ESPAÇO URBANO NA CAMINHABILIDADE
}

\author{
Jéssica Gomes de Lucena \\ Universidade Federal de Pernambuco \\ Orientador: Zeca Brandão \\ jessicaglucena@gmail.com
}

\begin{abstract}
RESUMO
O automóvel particular, anteriormente tido como símbolo da mobilidade é hoje visto como vilão da mobilidade. Ao buscar soluções para a crise da mobilidade é pertinente incentivar os modais ativos e o transporte público. Para avançar na mudança de paradigma, partindo da cidade carrocrata em direção à cidade caminhável, é oportuno estudar os fatores que interferem nos deslocamentos pedonais. Esta pesquisa compreende como objetivo geral identificar as relações de influência do espaço urbano nos deslocamentos pedonais, e faz parte de projeto de mestrado, de mesmo título e tema, em estado inicial. As variáveis utilizadas para investigar as influências na caminhabilidade foram definidas a partir da revisão bibliográfica. O estudo realizado no bairro da Torre, na cidade de João Pessoa - PB, contará com a participação de pedestres, além da avaliação técnica. Ao final, a hipótese, de que os espaços de transição entre o público e o privado possuem maior influência nos deslocamentos pedonais que a própria estrutura viária, será refutada ou confirmada.
\end{abstract}

Palavras chave: Caminhabilidade, desenho urbano, pedestres, mobilidade urbana.

\begin{abstract}
The private car, formerly seen as a symbol of mobility, is now seen as a mobility villain. When pursuing solutions to the mobility crisis it is important to foster active modes and public transport. To advance in the paradigm shift, starting from a car-depent city to a walkable city, it is opportune to study the factors that impair in the pedestrian displacements. This research' general objective is to identify the influential relations between urban space and the pedestrian displacements, and it is part of an master project, with the same title and theme, in an initial stage. The variables used to investigate influences on walkability were defined based on the literature review. The study area is the neighborhood of the Tower, in the city of João Pessoa - PB Besides a technical evaluation, the study will have the participation of pedestrians. In the end, the hypothesis that the spaces of transition between public-private are the variables of urban space that most influence pedestrians' displacements will be refuted or confirmed.
\end{abstract}

Key words: walkability, urban design, pedestrian, urban mobility. 


\section{INTRODUÇÃO}

As cidades surgiram como "resultado da troca entre viajantes pelos caminhos e comerciantes vendendo os seus produtos em bancas. Depois, as bancas se tornaram prédios e os caminhos viraram ruas, porém a troca entre quem veio e foi e os que ficaram continuou sendo o elemento chave" (STIPO, 2015:29). Juntamente às cidades surgiram as ruas, que abrigavam, primordialmente, os pedestres. Até a metade do século XX, a rua representava um sistema integrado de movimento e de vida social e dinâmica.

O caminhar é a forma mais natural de se locomover e era o principal meio de deslocamento nas áreas urbanas, até o surgimento das novas tecnologias de transporte, desenvolvidas nos finais dos séculos XIX e início do XX. A partir disso, as atitudes com relação ao espaço público mudaram e intervenções, de grande escala e focadas no trânsito, minaram a importância da rua para as trocas sociais e econômicas, consequentemente, os pedestres deixaram de interferir e participar das cenas urbanas para tornarem-se espectadores. Fatores como o desenvolvimento de novas tecnologias relacionadas aos transportes, a ampliação de rede viária e a aplicação de zoneamento monofuncional promoveram uma expansão urbana de modelo disperso e segregado. E nesse modelo de ocupação e expansão, o pedestre foi sendo deixado de lado para abrir espaço para projetos viários.

"Particularmente na América Latina se privilegiaram os modos motorizados em detrimento dos pedestres e ciclistas, apesar destes serem mais numerosos e vulneráveis" (Rodrigues et al., 2013:65). Os legados do planejamento dominado por carros são ainda bastante visíveis nas cidades ao redor do mundo. Os efeitos negativos do intenso uso do automóvel na vida urbana são significativos, consumo de combustíveis não renováveis, poluição atmosférica e sonora, causa de morte prematuras no trânsito. Os congestionamentos são um enorme problema, e gasto, para as cidades. O desenvolvimento de estilos de vida dependente de automóveis contribui para o declínio das atividades físicas e o aumento da obesidade. E o espraiamento urbano, resultado de uma cultura urbana carrocrata, leva ao isolamento social e a desconexão de comunidades.

A maioria das cidades tomou para si a escala motorizada, deixando de proporcionar uma cidade agradável para pessoas e nesse contexto de espaços concebidos para os veículos o pedestre assumiu um caráter de exceção. $\mathrm{O}$ afastamento da escala humana em detrimento da adequação à escala motorizada é uma questão inerente às transformações urbanas.

Nos anos sessenta e setenta, Jane Jacobs e Kevin Lynch criticam o planejamento modernista, questionam a segregação e defendem a manutenção da diversidade e vida nas ruas, apontando a necessidade de atentar à escala humana e a possibilidade de vivenciar a cidade ao nível dos olhos, fora dos carros.

As principais cidades da América do Sul possuem infraestrutura que favorece a utilização do automóvel. A predominância do automóvel particular na circulação viária é um problema recorrente na maioria das cidades brasileira de médio e grande porte. Em algumas delas, o número de automóveis cresce mais rapidamente que o número de habitantes. Nos últimos anos no Brasil, o aumento no número de veículos automotores foi 10 vezes maior do que o aumento da população (Brasil, 2010). Enquanto a população aumentou em 12,2\% em uma década (2000-2010), o aumento no número de veículos motorizados foi de $138,6 \%{ }^{1}$. Esses números do aumento da frota veicular são resultados de um modelo rodoviarista, que caracteriza historicamente a política de mobilidade no Brasil, e tem reflexos significativos na estrutura urbana das cidades brasileiras.

Entretanto, diante dos visíveis problemas causados pelo uso exacerbado do automóvel particular, como congestionamentos e poluição, este que era símbolo da mobilidade e da liberdade individual é hoje visto como "vilão" da mobilidade. A alteração nos padrões atuais de mobilidade, através do incentivo aos modos mais sustentáveis e ativos, é uma opção para mitigar os efeitos negativos dos padrões que incentivavam o transporte motorizado individual. Andar a pé oferece múltiplos benefícios para os pedestres, a sociedade e a cidade, como melhoria na qualidade de vida, redução dos custos de transporte, redução de impactos ambientais, maior oferta de equidade de acessos às atividades urbanas, além de que, economicamente, o valor dos investimentos em infraestrutura para os pedestres é inferior aos valores demandados pelos outros modais (gráfico 01). A presença dos pedestres nas ruas também influência na sensação de segurança e na atratividade dos espaços públicos.

\footnotetext{
${ }^{1}$ Dados do Instituto Brasileiro de Geografia e Estatistica (Brasil, 2010) e Departamento Nacional de Trânsito (Brasil, 2016)
} 


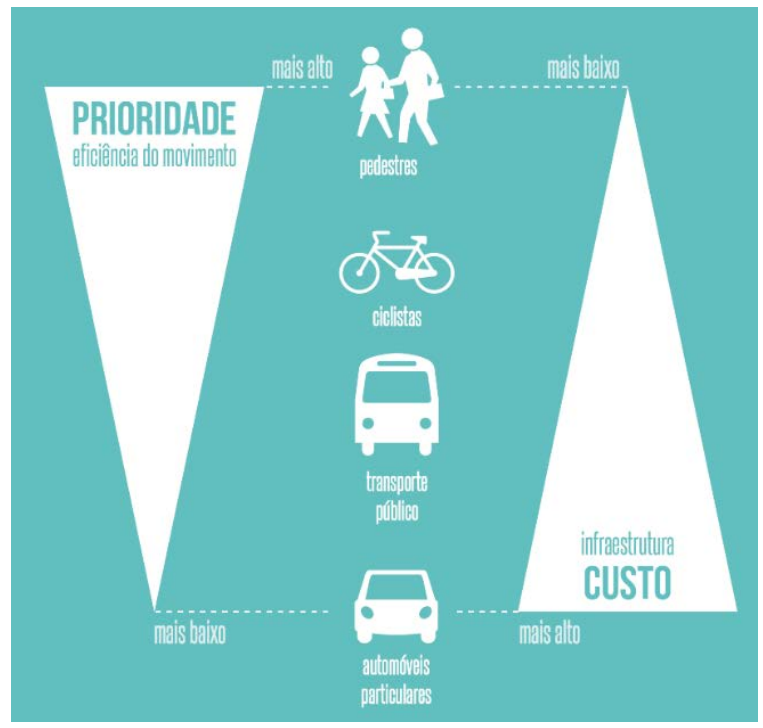

Gráfico 01: Pedestres como prioridade nas ruas (Lucena, 2016:21)

Andar a pé constitui uma forma indispensável de transporte e toda viagem urbana envolve uma caminhada, seja quando a viagem é realizada somente a pé ou como modo complementar a outros modos. Mesmo sendo responsáveis por grande parte dos deslocamentos urbanos (gráfico 02) - a média brasileira aponta que 36\% se locomove a pé ${ }^{2}$ - os pedestres ainda são muito vulneráveis no trânsito. Nas grandes cidades brasileiras, de $60 \%$ a $80 \%$ das mortes em acidentes correspondem a pedestres atropelados. Em tese, o pedestre é o elemento prioritário dentro do sistema de transporte e, portanto, deve ser incluído na análise e planejamento urbano, tendo suas características e necessidades respeitadas para que haja uma integração com os demais elementos do sistema.

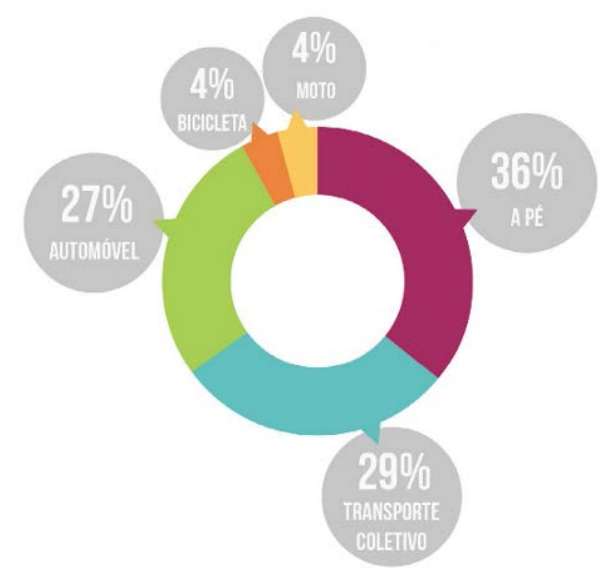

Gráfico 02: Divisão modal no Brasil - 2013 (Lucena, 2016:20)

Os estudos e práticas de Jane Jacobs, Jan Gehl, Kevin Lynch e Gordon Cullen influenciaram outras pesquisas e ações, e percebe-se, a partir do final da década de 80 , o surgimento de novos movimentos que tem em comum "a busca da sustentabilidade por meio de um planejamento que responda de forma integral à realidade política, social, econômica e ecológica das cidades" (Rodrigues et al., 2013:66). Essas correntes de pensamento são conhecidas por Novo urbanismo, New Traditional Neighborhood Design, Smart Growth, Transit Oriented Development e Livable Communities. Esses movimentos são direcionados às cidades sustentáveis, e fomentam desenhos urbanos que promovam a caminhabilidade e, consequentemente, vitalidade urbana. Uma preocupação crescente com a dimensão humana no planejamento urbano reflete uma exigência por melhor qualidade de vida na cidade. 
As políticas públicas devem seguir as tendências dessas correntes de pensamento voltadas às cidades sustentáveis de modo a alcançar uma mudança de paradigma ainda vigente, de priorização do automóvel. Para lograr nesta mudança, partindo de um modelo de cidade com cultura carrocrata em direção a uma cidade caminhável e humana, é oportuno estudar os fatores que interferem na caminhabilidade ${ }^{3}$. Segundo Jeff Speck, a caminhabilidade tanto contribui com a vitalidade urbana, como também é um indicador dessa vitalidade, portanto "Garanta uma caminhabilidade adequada e muito do restante virá (Speck, 2016:14). A caminhabilidade pode ser entendida como um meio para melhorar o espaço público. Resultados de pesquisas ressaltam os benefícios da caminhabilidade na área social, econômica, ambiental e política.

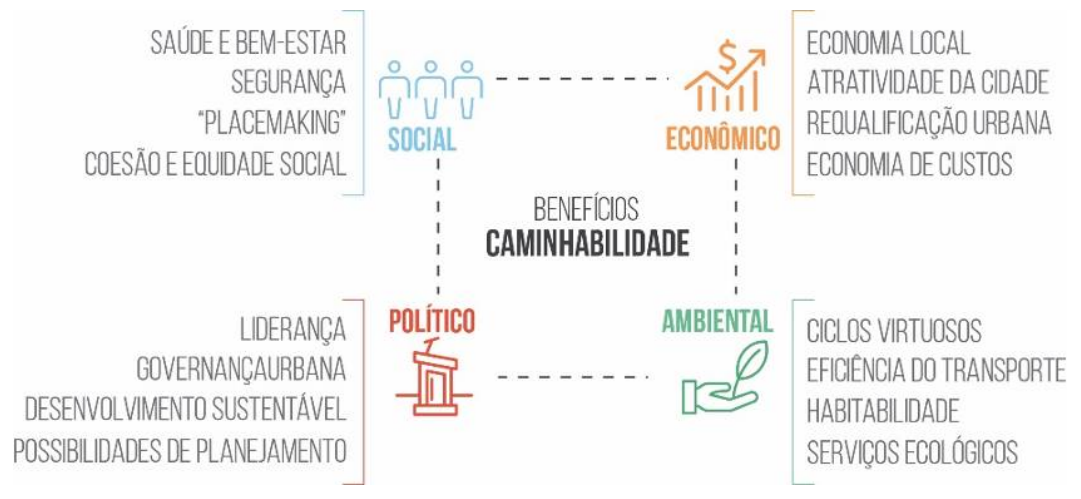

Gráfico 03: Áreas de benefícios da caminhabilidade

Elaborado pela autora, com base em ARUP (2016)

Portanto, para que haja avanços em direção a espaços caminháveis, e consequentemente mais sustentáveis, é primordial estudar os fatores que influenciam na experiência do pedestre e que podem contribuir para projetos de vizinhanças mais atrativas, políticas urbanas mais igualitárias e transporte mais acessíveis.

A mobilidade não está relacionada apenas à infraestrutura de transportes, os modos de deslocamento têm relação direta com a qualidade ambiental, derivada de um desenho urbano estruturador. A estruturação das cidades, consequência do planejamento, interfere qualitativamente na vida dos cidadãos. Estudos de qualidade urbana definem fatores de espaço urbano que são cruciais para a caminhabilidade e alguns destes sugerem relações com o ambiente construído e a promoção do deslocamento a pé.

Em consonância com a busca por cidades caminháveis e sustentáveis, e seguindo vertentes de outros estudos da área, este trabalho se propõe a investigar a relação de fatores do espaço urbano na caminhabilidade. O problema da pesquisa proposta se insere nos estudos de mobilidade urbana e desenho urbano. Tendo como objetivo geral comprovar que variáveis do espaço urbano, em especial, os espaços de transição entre o público e o privado, influenciam os deslocamentos pedonais, de modo a subsidiar intervenções que visem a melhoria da caminhabilidade. Estas variáveis do espaço urbanos estão relacionadas ao desenho urbano. Essa definição dos fatores referentes ao desenho urbano parte da premissa que a mobilidade urbana não está relacionada apenas à infraestrutura de transporte, mas sim a uma complexa estrutura urbana, consequência de um desenho urbano. Os modos de deslocamento são reflexos da forma urbana, assim como as dinâmicas da vivência na cidade.

Para que este objetivo seja alcançado há objetivos específicos a serem galgados, são eles: (a) averiguar as concepções do termo "caminhabilidade" e "espaços de transição", (b) caracterizar os espaços de transição no contexto do local de estudo, (c)analisar a influência desses espaços nos deslocamentos pedonais no bairro Torre, (d) identificar as variáveis urbanas e suas relações com os deslocamentos pedonais, com base nas variáveis do espaço urbano em estudo, (e) caracterizar as percepções dos pedestres quanto aos seus deslocamentos, (f) sistematizar diretrizes para melhoria da caminhabilidade na área de estudo.

Em virtude da natureza deste trabalho, uma dissertação de mestrado, o objeto de estudo se restringirá a análise de uma região em escala de bairro, porém sem desconsiderar as influências diretas de outras regiões próximas. O recorte espacial definido para o estudo de caso refere-se ao bairro da Torre, localizado na porção noroeste da cidade de João Pessoa, capital do nordeste brasileiro. A escolha deste bairro se deu devido a sua característica de subcentro, sua localização estratégica e integração no conjunto da cidade e seu importante papel na história do processo de ocupação cidade. Também foi fator decisivo a ocorrência momentânea de obras de mobilidade urbana, por parte da Prefeitura Municipal, em trechos do bairro.

\footnotetext{
${ }^{3}$ Caminhabilidade representa uma medida multidisciplinar do quão amigável à caminhada é uma área, levando em consideração um complexo e variado conjunto de características para sua avaliação. (ARUP, 2016:18)
} 


\section{FUNDAMENTAÇÃO TEORICA}

Neste ponto apresento uma revisão teórica acerca de conceitos abordados no estudo, relacionados à caminhabilidade e estrutura urbana. Para esta revisão foram consideradas pesquisas que abordem a temática da caminhabilidade, a mobilidade de pedestres e a qualidade do espaço urbano.

\subsection{Caminhabilidade}

"A palavra 'andabilidade' é uma tradução que não alcança plenamente os conceitos envolvidos no termo inglês walkability mas é um bom modo de começarmos a falar sobre um princípio fundamental das boas cidades, presente nas estruturas urbanas tradicionais, que é a qualidade do caminhar, da acessibilidade à cidade para qualquer tipo de pessoa, de qualquer idade, com qualquer tipo de dificuldade motora. É um conceito também sobre a facilidade de ter acesso a bens e serviços através do espaço público, sobre proximidade e interação entre pessoas, sobre sentir-se seguro e livre" (Fajardo, 2015: n.p.).

Chris Bradshaw (1993) foi o precursor da possibilidade de mensuração da walkability, desenvolvendo uma metodologia de sistema de avaliação, com base em um índice, para aplicação prática e direta ao seu contexto. Segundo Bradshaw (1993), a 'walkability' tem quatro características básicas: "(1) Um microambiente agradável ao pedestre: calçadas largas, pequenas interseções, faixas de carros estreitas, boa iluminação e ausência de obstruções; (2) Uma variedade de destinos uteis, em uma distância caminhável: comércios, serviços, empregos, escritórios, recreação, etc.;(3) um ambiente natural moderado, protegido das intempéries, sem excessos de poluição sonora, visual ou atmosférica; (4) Cultural local socialmente diversificada, pois isso aumenta o contato entre as pessoas e as condições para a coesão social" (BRADSHAW, 1993: n.p, tradução nossa).

Em 1992, na cidade de Ottawa, Canadá, os proprietários de imóveis e comerciantes enfrentaram grandes aumentos em seus impostos sobre propriedades, que tinham como base o valor de mercado. Os comerciantes passaram a questionar sobre a relação entre o valor de mercado e o imposto, argumentando que o valor de mercado não refletia na capacidade de pagamento de impostos. Outros ainda argumentavam que a maioria dos habitantes do bairro realizava seus deslocamentos diários caminhando, por isso não havia necessidade de pagar impostos altos sobre a infraestrutura para circulação de veículos (Ghidini, 2011).

Bradshaw (1993) viu a oportunidade de mensurar a caminhabilidade como um sistema de avaliação para calcular os valores de impostos em função de seu grau aplicado às quadras do bairro. $O$ índice criado poderia ainda ser útil a compradores de imóveis, para fazer uma avaliação da qualidade urbana do entorno, avaliando condições de segurança e qualidade e eficiência do transporte público. Bradshaw (1993) pensou nesse indicador como válido para uma ação coletiva, pois assim que o índice fosse aplicado a todo um bairro, ao longo do tempo os bairros poderiam melhorar os indicadores através de mudanças. Conforme Ghidini (2011) a caminhabilidade deve proporcionar uma motivação para induzir mais pessoas a adotar o caminhar como forma de deslocamento efetiva, restabelecendo suas relações interdependes com as ruas e bairros. Verificase a utilização de indicador denominado caminhabilidade como medida e referência à qualidade de vida no meio urbano, também como ferramenta objetiva de gestão para o desenvolvimento sustentável (Ghidini, 2011), relacionando-se com a necessidade de adotar padrões universais e estabelecer diretrizes para as intervenções nos espaços públicos das cidades (Silva et al., 2012).

Bradshaw popularizou o termo "caminhabilidade", e algumas derivações, como "caminhável", se tornaram usuais em estudos de planejamento urbano, engenharia urbana e até saúde pública. A caminhabilidade e a qualidade ambiental que ela significa passou a ser compreendida como um importante indicador de sustentabilidade urbana e inserida nos conceitos trabalhados dentro de linhas de pesquisa, como "Novo Urbanismo", "Vizinhanças amigáveis" e "Cidades Vivas".

"Ainda resta alguma ambiguidade em relação aos fatores e medidas a serem utilizadas para medir caminhabilidade. O que hoje é entendido como "cidade caminhável" ou um "bairro caminhável" engloba todas as dimensões de Bradshaw, geralmente referindo-se a ambientes urbanos densos, com edificações compactas próximas umas às outras, ocupadas por atividades comerciais em seus térreos, com calçadas movimentadas, boa iluminação e tratamento do espaço público e pequeno volume de tráfego motorizado" (Vargas, 2015: 24).

Para Vargas (2015) a descrição acunhada por Bradshaw contempla diversas escalas e mistura fatores, que para ele podem ser melhor organizados em diferentes dimensões da chamada "estrutura urbana". A dimensão 
urbana mais associada ao termo caminhabilidade é a distribuição dos usos do solo, a avaliação dos lugares dando ênfase as atividades existentes no local. Para efeitos positivos da caminhabilidade, as zonas com atividades variadas são preferíveis em detrimento a zonas monofuncionais. Muitos e variados destinos localizados a curta distância e alcançáveis a pé são vistos como positivo nos estudos técnicos-científicos, mas também apresentam seu apelo comercial. A publicidade de uma vizinhança com comércios e transporte acessíveis a uma distância caminhável está conquistando a sociedade contemporânea e sendo cada vez mais utilizada no mercado imobiliário.

Nesse sentido, foi criada em 2007, em Seattle, o WalkScore. Trata-se de uma ferramenta online utilizada para a avaliação da caminhabilidade, medindo a partir da pesquisa por endereço, inserindo em uma escala de 0 a 100 , onde quanto maior a pontuação menor a necessidade de deslocamentos motorizados e mais amiga do pedestre é a área avaliada (Machry; Monteiro, 2014). No WalkScore, informações de sistemas abertos de pesquisa do Google Maps como acessibilidade ao transporte público e rotas de pedestres até estabelecimentos são utilizadas como critérios de avaliação. Portanto, quanto maior a quantidade de amenidades a uma distância curta, maior será a pontuação do endereço avaliado. "Além disso, o site também mede o quão amigável os lugares são, com base em dados de densidade populacional e geometria do espaço urbano, considerando tamanhos de quadras e densidades de cruzamentos" (Machry; Monteiro, 2014: 03). "Este serviço já está consagrado como referência para a compra, venda e locação de imóveis em diversos países" (Vargas, 2015: 24). A metodologia de avaliação do WalkScore responde às questões de cidades norte-americanas, com problemas urbanos específicos à sua realidade de ocupação do espaço. Porém, mesmo com a utilização de critérios de avaliação em áreas com realidade diferentes é possível consultar endereços em diversos países.

Analisando a caminhabilidade e a qualidade do ambiente do pedestre na microescala é possível encontrar abordagens que privilegiam fatores locais que proporcionam viagens a pé seguras, confortáveis e agradáveis: "A forma dos edifícios, o mobiliário urbano, a vegetação, a sinalização, a qualidade das calçadas e o tratamento dos espaços públicos são aspectos que podem indicar a satisfação do pedestre com o ambiente e a viabilidade de realizar viagens a pé que a acessibilidade viária, as atividades e a densidade potencialmente induzem" (Vargas, 2015: 25)

Krambeck (2006) privilegia outros aspectos, como segurança, conveniência e atratividade, e afirma que a segurança viária, a proteção climática e a livre circulação devem ser priorizados e privilegiados através de ações de curto e médio prazo, e em comparação à aspectos que só podem ser alterados através de políticas de longo prazo, como mudanças de uso do solo e zoneamento. Essa abordagem que centraliza a segurança viária como principal aspecto da caminhabilidade é trabalhada por diversos autores, dentre eles Reid Ewing (1999), com seu trabalho intitulado "Pedestrian and Transit Friendly Design: a primer for smart growth", e John Fruin (1971) sendo o primeiro autor a adaptar o conceito de nível de serviço para pedestres dento do "Highway capacity manual (HCM)". Ewing também trabalha com o conceito de atratividade, uma qualidade subjetiva referente à qualidade dos espaços em termos da possibilidade de fruição da cidade. Ambientes aprazíveis permitem o uso das calçadas não apenas para passagem, mas também para encontros e relações sociais e econômicas, produzindo áreas urbanas animadas e vivas, nas quais o comércio e demais atrações estão inseridas em edifícios atraentes, com calçadas largas, árvores e paisagismo (Vargas, 2015). O fato das pessoas serem atraídas para caminhar e permanecer no espaço da cidade é muito mais uma questão de trabalhar cuidadosamente com a dimensão humana.

Para Gehl (2013) e Speck (2016) há muito mais em caminhar do que simplesmente andar, envolve experiências. Há uma troca entre as pessoas e a comunidade do entorno, as experiências e prazeres gratuitos da vida. "Moradores urbanos experienciam as suas cidades no que chamamos de a 'esfera pública"' (STIPO, 2015:15) e essa "esfera pública" tem um significado maior do que somente 'espaço público'; inclui fachadas, mobiliários e tudo que pode ser visto ao nível dos olhos. As zonas híbridas (gráfico 04) são nomeadas por Gehl como "espaços de transição" entre o público e o privado. Para Gehl (2013) a forma como esses espaços são desenhados e trabalhados é determinante para boas cidades. "A interface que a dimensão privada a eles oferece - janelas, olhos, permeabilidade ao invés de muros, grades, barreiras" (Gehl, 2013:13) é importante para a vitalidade dos espaços urbanos. 


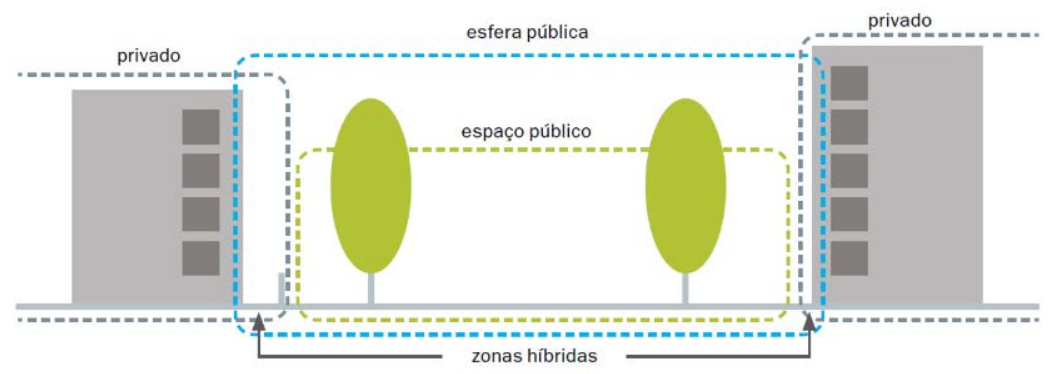

Gráfico 04: Esquema esfera pública

(Stipo, 2015: 15)

\subsection{Mobilidade pedestre e a estrutura urbana}

Vários estudos abordam a relação da estrutura urbana e as viagens não motorizadas, em particular as viagens a pé. Estes estudos são importantes para uma fundamentação teórica que ampara o trabalho de planejadores urbanos em decisões práticas sobre as políticas urbanas. A literatura aponta diversas pesquisas que relacionam e investigam a relação de influência da estrutura urbana nas viagens a pé, porém a maioria dos estudos desenvolvidos aborda cidades de países desenvolvidos, muitas delas nos Estados Unidos. Frank e Pivo (1995) testaram o impacto em Washington, Cervero e Radisch (1996) e Cervero e Duncan (2003) estudaram a relação para a cidade de São Francisco. Cao et al (2006) analisaram em Austin, Texas, enquanto Hammond (2005) avaliou a relação na cidade de Cardiff. A pluralidade de estudos encontrados mostra evidências de que existe influências do espaço urbano sobre os deslocamentos a pé, e que alterações na estrutura da cidade podem alterar os padrões de deslocamento desses pedestres. Também foram encontrados estudos realizados no Brasil, como os desenvolvidos por Amâncio e Sanches (2008) para a cidade de São Carlos - SP, Larrañaga (2012) que estudou a relação entre a estrutura urbana e viagens a pé na cidade de Porto Alegre - RS, e Fernandes et al (2008) investigaram a relação entre a forma urbana e o transporte no município de Olinda - PE. A maioria desses estudos relacionam quantitativamente variáveis do ambiente construído e o comportamento de viagens, especialmente a pé.

Segundo Amâncio e Sanches (2008) a premissa básica da maioria desses estudos é que "as características locais da forma urbana podem influenciar o comportamento de viagens de três modos básicos: (1) reduzindo o número de viagens motorizadas; (2) aumentando a parcela de viagens não-motorizadas; e (3) reduzindo as distâncias de viagem em veículos motorizados" (Amâncio; Sanches, 2008:148).

Um dos primeiros e mais importantes estudos dessa linha de pesquisa é o desenvolvido por Cervero e Kockelman (1997) e denominado "Travel Behavior and the 3Ds", no qual a influência da estrutura urbana no padrão de viagens é analisada através de características/dimensões que começam, em inglês, com a letra "D". Cervero e Kockelman definiram as principais dimensões da estrutura urbana como sendo: Density (densidade), Diversity (diversidade) e Design (desenho urbano). Posteriormente, Ewing e Cervero (2001, 2010) adicionaram outras duas dimensões, formando o modelo "5Ds", e obtiveram resultados significativos em seus estudos, são elas: Destination accessibility (acessibilidade ao destino) e Distance to transit (distância ao transporte público). Utilizamos o termo "5Ds" para se referir a estas variáveis da estrutura urbana, descritas a seguir. Cada $D$ pode ser caracterizada através de variáveis internas.

Densidade é a medida que expressa o número total da população em uma determinada área urbana. É sempre medida através de um quociente entre a variável de interesse e a unidade de área, pode ser expressa em habitantes por unidade de terra ou total de unidades construídas sobre uma área. Há um efeito positivo da densidade no fomento de viagens a pé pois áreas com alta densidade significa maior concentração de pessoas, o que significa maior potencial de geração de viagens (Ewing et al., 2009; Larrañaga et al., 2009).

O termo diversidade refere-se à diversidade do uso do solo e existe associada à densidade. É o grau de mistura de usos do solo em uma determinada área, e "no caso de uma alta miscigenação de atividades, aproximando origens e destinos, aumenta a probabilidade de realizar viagens com modos não motorizados" (FRANK et al, 2006 apud Vargas, 2015: 27).

Entende-se desenho urbano por meio das propriedades da malha viária e configuração das vias da área de estudo. "Utiliza-se medidas objetivas como o percentual de esquinas em cruz ou "T" (cruzamento de quatro 
ou três vias), densidade de interseções, tamanho médio dos quarteirões, conectividade das vias, densidade do sistema viário e também classificações qualitativas como tipo de malha "em grelha" ou "com curvas"' (Vargas, 2015: p.27). Na literatura pesquisada, é possível verificar que o padrão viário em forma de grelha é mais eficiente para incentivar as viagens a pé, pois oferece maior variedade de opções de rotas (Cervero e Kockelman, 1997; Amâncio e Sanches, 2008). Segundo Krizek (2003) e Rodrigues et al (2014) é preferível medir a influência do desenho urbano nas viagens a pé pelo tamanho dos quarteirões ou pela intensidade de interseções do que por sua forma geométrica. A sintaxe espacial pode ser utilizada para medir a conectividade e as propriedades configuracionais, como níveis de integração e profundidade, das redes viárias.

Uma ressalva quanto ao uso do termo "Desenho Urbano", como tradução do termo em inglês "Design", no modelo "5Ds" de análise. Compreende-se desenho urbano como um campo multidisciplinar, que trata das dimensões físico-espaciais da cidade, e é parte integrante do processo de planejamento. Por ser multidisciplinar e lidar com a qualidade do meio ambiente, o desenho urbano envolve uma gama enorme de aspectos do urbano. Na nossa percepção, todas as variáveis citadas no modelo "5Ds" poderiam ser consideradas como oriundas do Desenho Urbano, e a adoção deste termo é, basicamente, uma questão de tradução que buscou utilizar um termo, em português, que também inicia com a letra $D$.

A variável "distância ao transporte público" representa a acessibilidade ao transporte público, medida através da distância média do domicilio até a parada de ônibus mais próxima. Larrañaga et al (2009) sugere testar outros indicadores da disponibilidade de transporte coletivo, como uma variável que combine tempo de acesso e espera por serviços de transporte público, onde o tempo de acesso pode ser obtido através de informações demográficas e localização das paradas de ônibus, e o tempo de espera pode ser determinado em função da regularidade das linhas que atendem esses destinos.

O indicador "acessibilidade ao destino" busca medir a facilidade de acesso a oportunidades de viagens. Podendo ser uma acessibilidade local ou regional. Alguns estudos mensuram a acessibilidade regional através da distância ao centro comercial/administrativo mais próximo (Larrañaga; Cybis, 2010), enquanto a acessibilidade local é medida através da distância do domicilio até o comércio mais próximo (Ewing; Cervero, 2010).

Alguns autores utilizam variáveis de microescala (por exemplo: presença, qualidade e dimensão de calçada, ciclovias e/ou estacionamento, existência de faixas de segurança) dentro do indicador de Desenho Urbano. Larrañaga et al. (2009) sugere a inclusão de atributos urbanos referentes à qualidade das calçadas, como aspectos visuais e estéticos do ambiente e mobiliário urbano, qualidade do pavimento, presença de obstáculos (permanentes ou temporários) e largura das calçadas. A inserção dos atributos urbanos, recomendação de Larrañaga et al. (2009) está em consonância com o discurso de Vargas (2009) que afirma ser necessária uma abordagem ao nível local da rede de circulação que levará ao melhor entendimento das características da microescala do ambiente construído e de sua influência sobre as decisões dos indivíduos. Em contraposição, nos estudos desenvolvidos por Amâncio e Sanches (2008), baseados nos estudos de Cervero (2002), as evidências com relação as características da microescala, como presença e largura de calçadas e topografia, se mostraram inconclusivas ou apresentam ambiguidades teóricas e empíricas.

Segundo revisão teórica realizada por Vargas (2015) a maioria dos estudos realizados nos Estados Unidos afirma que uma maior atividade pedestre está associada com maiores densidades, maior numero de destinos comerciais/serviços em curta distância e um sistema viário bem conectado. Ainda segundo este autor, pesquisas realizadas em países subdesenvolvidos (Zegras, 2004; Larrañaga et al., 2009) concluíram que as viagens a pé estão mais relacionadas à diversidade de uso do solo, padrão viário em forma de grelha e destinos localizados proximamente.

Um ponto pouco abordado pelos autores expostos acima é a questão da influência dos espaços de transição, entre o edifício e o espaço público, na vida urbana. Autores como Jan Gehl, Jane Jacobs e Jeff Speck observam o efeito desses espaços de transição na urbanidade. Gehl (2010: 88) observa: "Nenhum tema tem mais impacto na vida e na atração exercida pelo espaço público do que esses espaços de transição, ativos, abertos e vivos", discorrendo sobre e apresentando métodos de estudos em sua obra Cidade para Pessoas. A esfera pública não é somente um entorno funcional, como também um entorno de experiências urbanas, e pesquisas recentes estão abordando as experiências vivenciadas ao nível dos olhos (Netto et al., 2012; STIPO, 2015; ITDP, 2016, 2018; MACHRY, 2016 e SPECK, 2016). O termo "plinth", cunhado pela Stipo (2015), deriva da palavra holandesa "plint" que significa rodapé, vem sendo utilizado para representar o andar térreo de um edifício, sendo a parte mais crucial para a cidade ao nível dos olhos, "cruciais para a experiência e atratividade do espaço urbano, seja em áreas residenciais ou comerciais" (STIPO, 2015, p. 15). 
"O que nós queremos do andar térreo é vastamente diferente do que queremos dos outros andares de um prédio. $\mathrm{O}$ andar térreo é onde o prédio e a cidade se encontram, onde nós moradores urbanos temos encontros imediatos com os prédios, onde podemos tocar e ser tocados por eles" (STIPO, 2015: 29). Neste estudo, o termo plinth é adotado para representar o espaço de transição, a interface, público-privado no nível térreo. O plinth se configura como o elo conector entre o edifício e a cidade.

Em extenso estudo realizado em três capitais brasileiras, Netto et al. (2012) investiga as consequências das implantações generalizadas dos edifícios isolados nos lotes e fechados para as ruas. Esse mesmo estudo revelou diversas implicações, como a redução do fluxo de pedestres, o estimulo ao uso do carro e a padronização e fragmentação de paisagens. Uma das hipóteses do estudo é que aspectos-chave do edifício, como sua implantação, seus acessos e a forma urbana, produzem efeitos locais positivos e negativos nas atividades na rua.

O Índice de Caminhabilidade, desenvolvido e aplicado pelo ITDP Brasil ${ }^{4}$, é composto por 15 indicadores, agrupados em 6 categorias. A categoria "Atração" inclui indicadores relacionados a características do uso do solo que influenciam a atratividade do deslocamento para os pedestres, avaliando atributos das edificações, como a permeabilidade visual e física das fachadas. A metodologia de avaliação e pontuação do índice propõe identificar e quantificar o número de entradas e acessos por face de quadra e de elementos considerados visualmente ativos no pavimento térreo.

Foi observada a escassa existência de estudos que relacionam a influência dos espaços de transição nos deslocamentos a pé. Especialistas urbanos dissertam acerca da importância de desenhar os térreos e trabalhar a cidade ao nível dos olhos para a vitalidade dos espaços públicos. A atratividade do nível térreo é diretamento derivada do tipo de uso existente no local, os espaços comerciais e de serviço apresentam maior preocupação em dispor de fachada ativa, atraindo usuários.

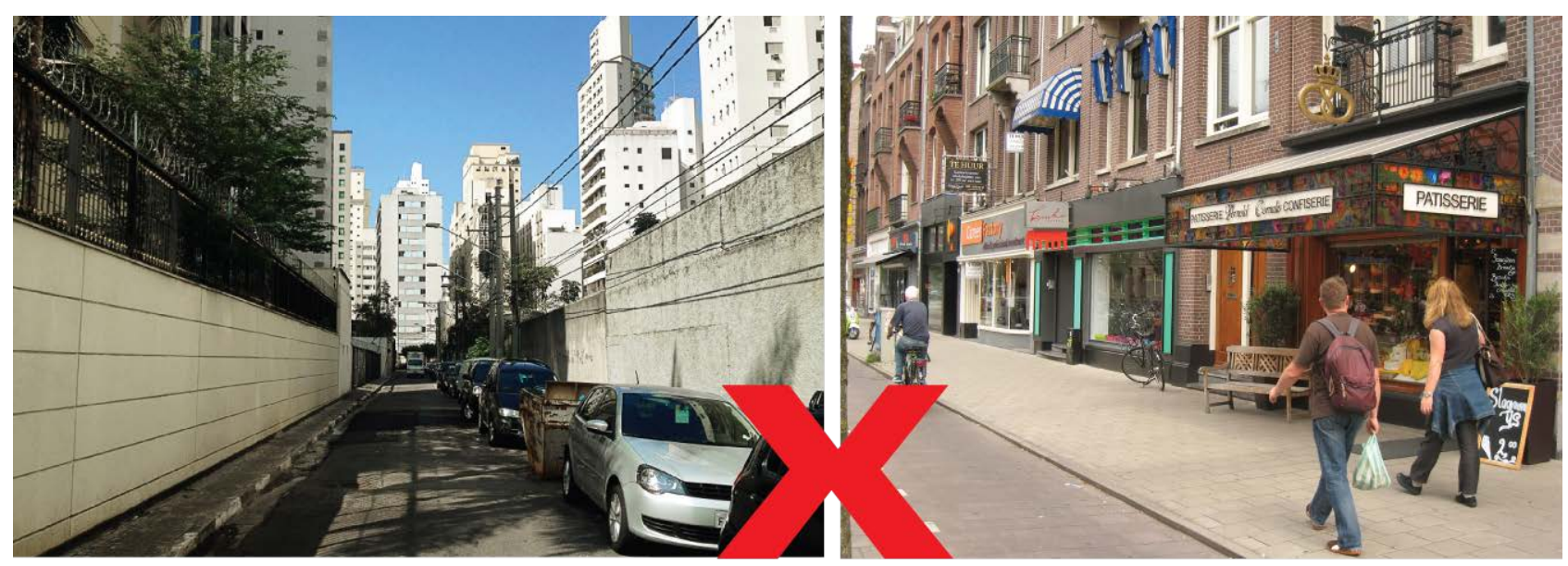

Gráfico 05: Espaços de transição que repelem pedestres $X$ espaços de transição que atraem pedestres. Elaborado pela autora, com base em STIPO (2015) e acervo pessoal

Além das variáveis relacionadas a estrutura urbana, é verificada a adoção de indicadores socioeconômicos na maioria dos estudos considerados nesta revisão bibliográfica (Ewing; Cervero, 2001, 2010, Zegras, 2004, Amâncio; Sanches, 2008, Larrañaga et al, 2009, 2010, Vargas, 2015). "As diferenças no padrão de viagens podem ser causadas fundamentalmente por esses indicadores e não apenas pelas características físicas do bairro de residência" (Larrañaga et al, 2009). Cao et al (2005) sugere a adoção de variáveis relacionadas a atitudes e estilo de vida dos indivíduos, e argumentam que certas famílias optam por residir em áreas especificas para poderem se deslocar mais a pé e evitar o uso do automóvel particular. Portanto, a inserção desses indicadores, socioeconômicos e atitudinais, deve se dar articulada às variáveis da estrutura urbana.

A partir dos autores citados acima é possível verificar a pluralidade de estudos que abordam as temáticas da caminhabilidade, a avaliação dos espaços de pedestres e relação das viagens a pé com a estrutura urbana.

\footnotetext{
${ }^{4}$ Instituto de Políticas de Transporte \& Desenvolvimento
} 
Cada estudo possui uma especificidade de indicadores e variáveis utilizadas, baseando-se nas particularidades dos locais onde os estudos estão sendo empregados e avaliados. Esta pesquisa de dissertação compreende como objetivo comprovar que os espaços de transição entre o público e o privado influenciam os deslocamentos pedonais, utilizando-se de indicadores e variáveis definidos a partir da revisão bibliográfica efetuada. A seção referente a metodologia da pesquisa apresenta os indicadores e variáveis selecionados para a realização da análise no recorte espacial definido.

\section{METODOLOGIA}

Esta pesquisa foi estruturada em quatro blocos principais. O primeiro bloco consiste em uma revisão conceitual e de referencial teórico relativa às temáticas abordadas na dissertação. O segundo bloco abrange pesquisa documental com objetivo de coletar dados iniciais referentes ao recorte espacial de estudo. A pesquisa de campo caracteriza o terceiro bloco. Neste, procedimentos de análise qualitativa e quantitativa serão empregados visando atingir os objetivos propostos na dissertação. O último bloco refere-se à realização da análise proposta, e tem como produto as respostas para os questionamentos apontados na pesquisa, e a consequente conclusão da dissertação.

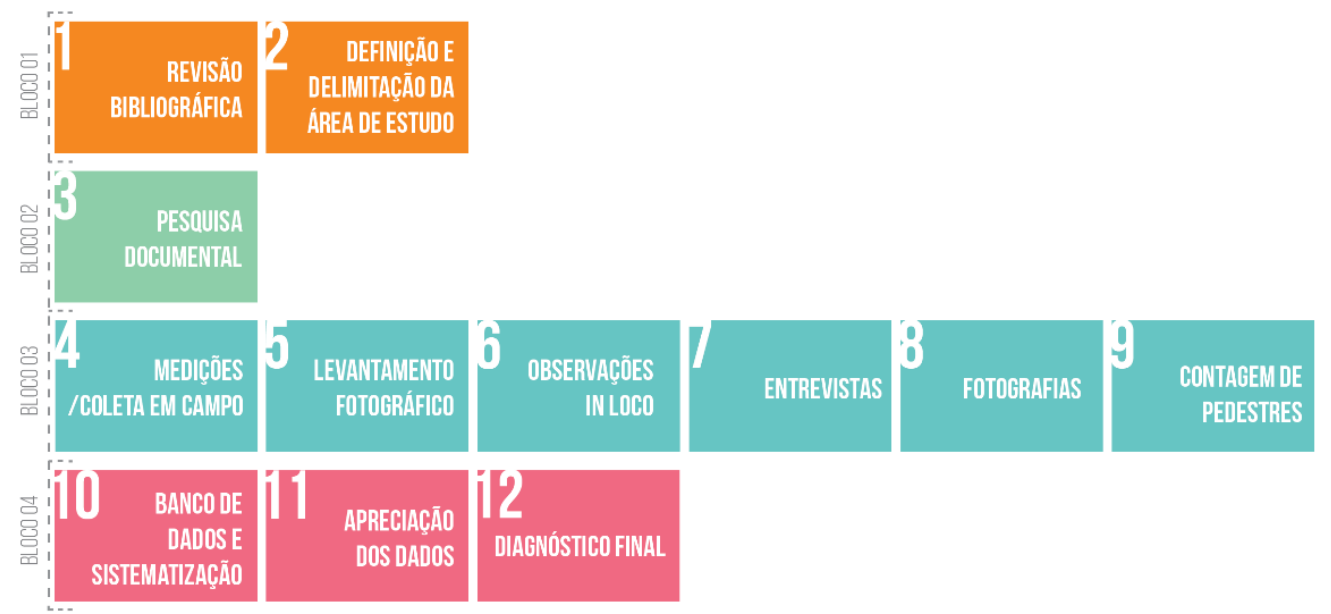

Gráfico 06: Etapas de trabalho

Elaborado pela autora

Bloco 01 - Revisão conceitual e bibliográfica: A revisão bibliográfica permitiu uma fundamentação teórica e maior proximidade com as técnicas e métodos utilizados por outros pesquisadores, sendo de fundamental importância para a definição da metodologia do trabalho. Esse bloco tem como produtos o embasamento teórico da pesquisa e a definição dos indicadores utilizados na pesquisa. As variáveis selecionadas e as fontes de obtenção dos dados são apresentadas no gráfico a seguir. 


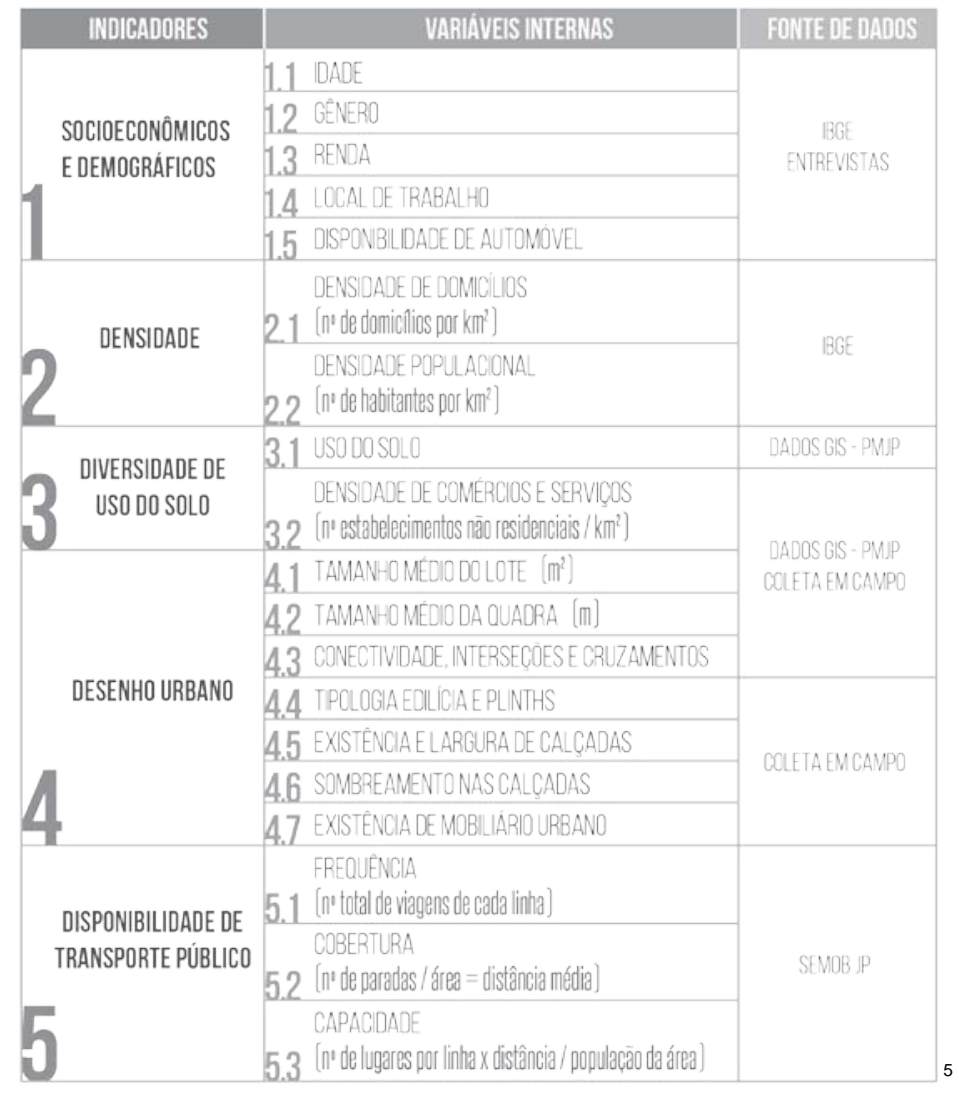

Gráfico 07: Indicadores e variáveis de estudo Elaborado pela autora

Seguindo as tendências observadas na revisão bibliográfica, serão consideradas, além das variáveis físicas da área de estudo, características socioeconômicas e demográficas da população, que inclui pedestres e moradores, analisada.

O modelo de "5Ds", visto na revisão bibliográfica, foi adaptado na definição dos indicadores e variáveis que serão utilizados na pesquisa. A principal adaptação foi o agrupamento de dois dos 5Ds, sendo eles: a "diversidade de uso do solo" (diversity) e a "acessibilidade ao destino" (destination accessibility). Esse agrupamento se deu pela proximidade de conteúdo entre os dois indicadores, ambos abordam os usos geradores de empregos ou não-residenciais, portanto, agrupa-los pareceu ser coerente. Outra observação quanto ao modelo "5Ds" é a utilização do termo "desenho urbano, optou-se por manter o termo para que não haja tamanha discordância com outras pesquisas relacionadas.

A inserção da variável 4.4 "Tipologia edilícia e plinths" se deu devido a sua relação direta com a hipótese central $^{6}$ da pesquisa, que também foi definhada a partir da pesquisa bibliográfica. As variáveis $4.5,4.6$ e 4.7 foram adicionadas em concordância com as pesquisadas realizadas por Larrañaga (2009) e Vargas (2015). Para estes autores é necessária uma abordagem ao nível local da rede de circulação, levando a um melhor entendimento das características da microescala do ambiente construído e de sua influência sobre as decisões dos indivíduos. Estas variáveis (4.4, 4.5, 4.6 e 4.7) do Desenho Urbano serão objeto de comparação direta entre si e com a variável Uso do solo, com o intuito de estabelecer relações e compreender qual variável apresenta maior influência nos deslocamentos dos usuários, buscando confirmar ou negar a hipótese central.

Definição e caracterização da área de estudo: Essa etapa tem como produto principal a delimitação e caracterização da área de estudo. A escolha do bairro da Torre, na zona noroeste da cidade de João Pessoa, se deu devido a um conjunto de condições, como sua característica de subcentro, sua localização estratégica

\footnotetext{
${ }^{5}$ IBGE: Instituto Brasileiro de Geografia e Estatística; GIS - PMJP: Sistema de informação geográfica do setor de Geoprocessamento da Prefeitura Municipal de João Pessoa; SEMOB JP: Superintendência Executiva de Mobilidade Urbana de João Pessoa

${ }^{6}$ Hipótese: "São os espaços de transição entre o público e o privado as variáveis do espaço urbano que mais influenciam nos deslocamentos pedonais"
} 
(gráfico 07) e seu papel na história do processo de ocupação cidade. Outro fator que contribuiu para a escolha deste bairro foi a ocorrência de obras de mobilidade, por parte da Prefeitura Municipal, em trechos desta área. Localizado vizinho ao bairro Centro, o bairro foi um dos primeiros bairros a serem planejados na capital e o início de sua ocupação se deu a partir dos anos 30 , porém a consolidação da ocupação do bairro ocorre, de fato, nas décadas de 1940 e 1950. O bairro da Torre está conformado entre três dos principais eixos estruturantes (Av. Epitácio Pessoa, Av. Min. José Américo de Almeida e Av. Dom Pedro II)(gráfico 08) da cidade e abriga boa parte dos comércios e serviços dispostos ao longo dessas vias, constituindo-se como um subcentro da cidade. A expressão subcentro é utilizada, por Flávio Villaça (2001), para designar aglomerações diversificadas e equilibradas de comércio e serviços, que não o centro principal. Por estar inserido na Macrozona adensável prioritária da cidade de João Pessoa, são permitidos usos residenciais, comerciais, serviços, institucionais de bairro e industrias não-poluentes, sendo cada uso regulamentado de acordo com o Código de Urbanismo.

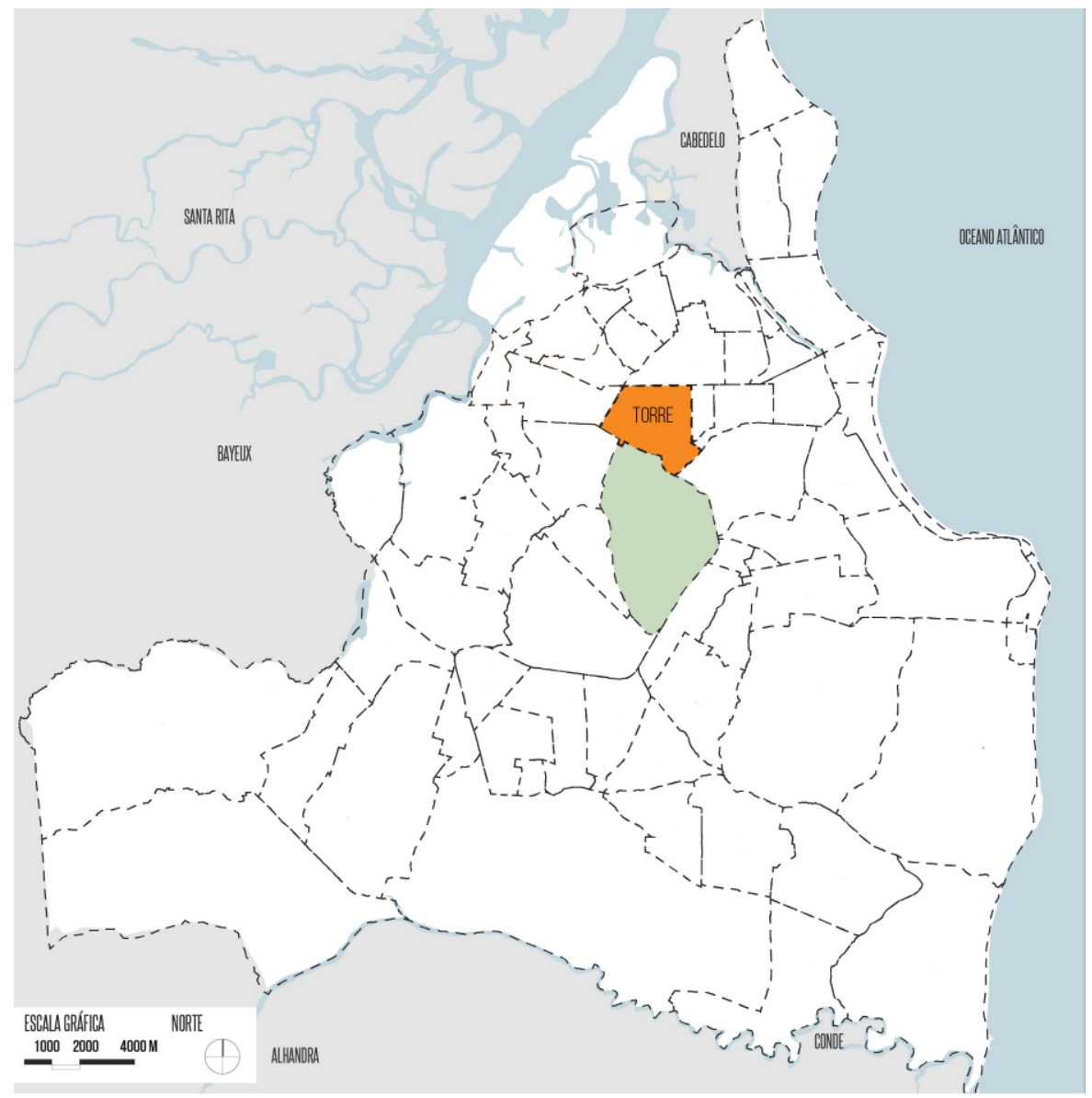

Gráfico 08: Localização do bairro Torre, destaque em laranja, na cidade João Pessoa. Elaborado pela autora com base em Lucena (2016) 


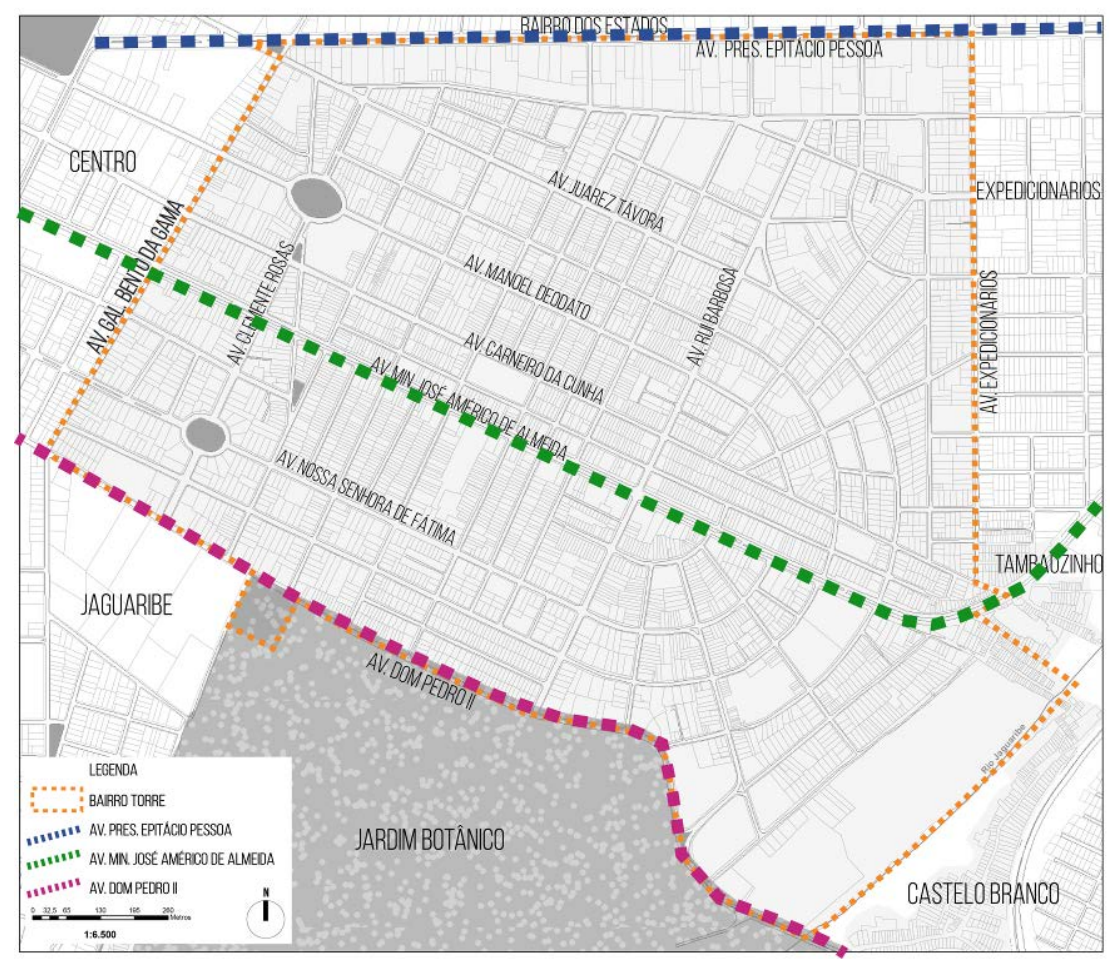

Gráfico 09: Limites do bairro Torre e eixos estruturantes.

Elaborado pela autora com base em mapa da Prefeitura de João Pessoa

Bloco 02 - Coleta de dados: Essa segunda etapa envolveu a coleta de dados iniciais referentes ao local de estudo, obtidos através de pesquisa documental. Esses dados iniciais são referentes aos dados censitários e estatísticos, como número de habitantes, número de residenciais, comércios e serviços cadastrados no local, oferta de transporte público. Os dados foram obtidos em arquivos públicos, institutos de estatísticas e publicações de órgãos responsáveis. Esses dados foram organizados para gerar mapas, imagens, croquis e diagramas, utilizados para a caracterização do bairro e a criação do banco de dados para a análise final. Esta etapa tem como produto principal um mapa base com informações básicas a respeito do bairro.

Bloco 03 - Pesquisa de campo: Definidos os fatores a serem analisados e com os dados referentes ao local de estudo organizados, a terceira etapa será constituída pela pesquisa de campo, utilizando diversas técnicas e procedimentos, apresentados a seguir. O objetivo geral desse bloco é realizar a pesquisa de campo e conseguir todas as informações necessárias de modo a organizar o banco de dados primordial à análise da pesquisa. Um objetivo específico da pesquisa é a compreensão das percepções e preferências dos pedestres quanto aos seus deslocamentos. Esse bloco tem como produto principal as informações para a elaboração do banco de dados.

Medições/Coleta em campo: Alguns dados obtidos através da pesquisa documental precisam ser verificados. O objetivo dessa etapa é a medição de elementos internos às variáveis de análise, e deve ser realizada para que estas analises sejam viáveis.

Levantamento fotográfico: O levantamento fotográfico é importante como forma de registro. O objetivo dessa etapa é obter registros fotográficos que auxiliem o levantamento de dados. O produto dessa etapa é um acervo de fotos a ser utilizado em diversas partes desse trabalho.

Observações: A técnica da observação será utilizada visando obter informações a respeito da dinâmica de deslocamentos no bairro, especialmente próximo aos centros atratores de fluxos, como mercados, escolas, hospital, entre outros), sendo uma observadora não participante.

Entrevistas: Alguns dados referentes às características socioeconômicas e atitudinais dos pedestres serão obtidos através de entrevistas individuais. O objetivo da utilização da técnica das entrevistas é explorar as perspectivas, opiniões e atitudes dos pedestres, de forma a auxiliar o entendimento acerca de seus deslocamentos. A população alvo da aplicação das entrevistas será composta por residentes e pedestres do bairro. Será utilizado um roteiro semi-estruturado, para assegurar que os tópicos de interesse sejam cobertos. 
As entrevistas devem investigar também aspectos socioeconômicos e demográficos, como localização da residência, sexo, faixa etária e posse de automóvel. Um pré-roteiro utilizado para orientar as entrevistas foi composto pelas questões apresentadas no quadro a seguir.

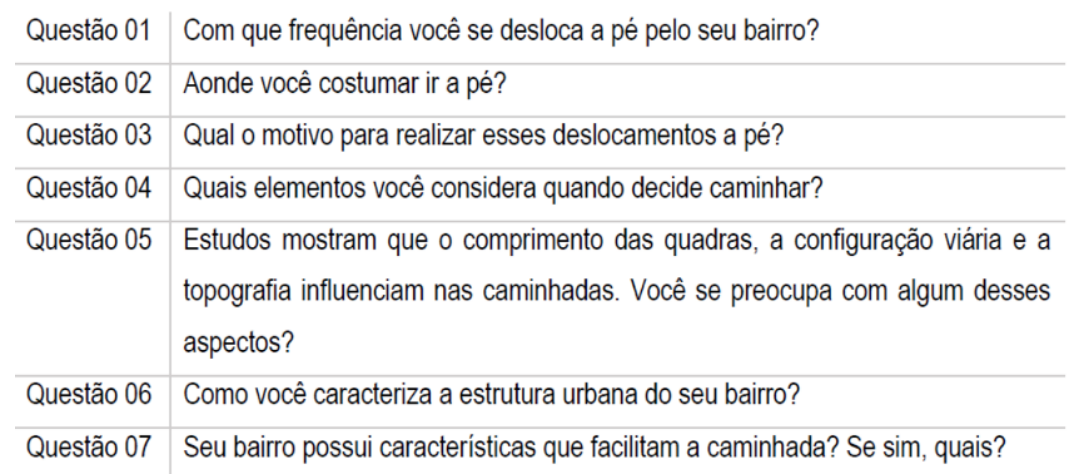

Gráfico 10: Pré-roteiro das entrevistas a serem realizadas

Elaborado pela autora

Fotografias: A técnica da fotografia consiste em apresentar fotografias aos pedestres e solicitar por informações que se fazem relevantes quanto ao local apresentado. Os pedestres serão questionados quanto à atratividade e a agradabilidade de locais posteriormente determinados. O objetivo da aplicação desta técnica é obter informações complementares às obtidas com as entrevistas, e de forma mais rápida e dinâmica que a aplicação das entrevistas.

Contagem de pedestres: O objetivo dessa etapa é apreender quantitativamente o fluxo de pedestres em determinadas áreas do bairro.

Bloco 04 - Análise final: Sistematização dos dados / Banco de dados: Para abordar os questionamentos levantados com a pesquisa será necessário organizar dados de diversas fontes e copilar todas as informações em um banco de dados. Cada fonte utilizada para coletar os dados está descrita na Tabela 03. Basicamente, cada variável possuirá um método de sistematização, e será necessário utilizar métodos quantitativos, empregando técnicas estatísticas, e qualitativos. O produto dessa etapa é o banco de dados organizado.

Apreciação dos dados: Esta pesquisa pretende adotar procedimentos distintos para a análise de dados quantitativos e qualitativos, tendo em vista o caráter específico de cada informação e das informações apreendidas ao longo das etapas de trabalho anteriores. Produto da etapa: análise preliminar dos dados.

Diagnóstico final: Nesta última etapa, as informações referentes aos objetos de estudo serão expostas e confrontadas visando relatar/reunir um repertório de informações relevantes ao tema, ou seja, as relações entre a caminhabilidade e as variáveis do espaço urbano encontradas no bairro analisado. Esta etapa terá como produtos as respostas para os questionamentos apontados na pesquisa e a conclusão desta.

\section{CONSIDERAÇÕES FINAIS}

Com o reconhecimento dos beneficios advindos dos deslocamentos ativos de pedestres, a promoção deste modal vem se tornando presente nas agendas públicas. A caminhabilidade, termo que representa uma medida do qual amigavel é caminha em uma área da cidade, é abordada como indicador e contribuinte da vitabilidade urbana. Cidades que visam uma mudança em direção a vitalidade, atratividade e sustentabilidade devem investir na caminhabilidade como meio de alcançar estes objetivos. Verificou-se a utilização da caminhabilidade como indicador da qualidade de vida no meio urbano, e como ferramenta para o desenvolvimento sustentavel, por meio da implantação de melhorias no espaço público.

Andar a pé constitui uma forma simples e indispensável de transporte. Ao considerar que toda viagem urbana envolve uma caminhada este modo se faz extremamente importante na mobilidade urbana. A média brasileira de deslocamentos a pé é de $36 \%$. Esse percentual varia conforme o porte da cidade e a condição socioeconômica dos indivíduos. O fato do aumento de $153 \%$ da frota veicular privada na cidade de João Pessoa - PB deve contribuir para que o percentual de pessoas que se deslocam a pé seja menor que os outros modais.

Este artigo aborda o processo de desenvolvimento de uma dissertação cujo objetivo é comprovar que dentre variaveis do espaço urbano, os espaços de transição tem maior influência nos deslocamentos pedonais. 
Apresentaram-se relevantes para o desenvolvimento da pesquisa, até o momento, a revisão bibliográfica e a definição da metodologia.

Distintos indicadores têm sido utilizados para avaliar as relações entre os deslocamentos a pé e a estrutura urbana. A partir de ampla revisão bibliográfica os indicadores e variáveis a serem utilizados nesta pesquisa foram definidos, caracterizados e organizados. A definição das variáveis permitiu melhor compreensão dos dados que deveriam ser levantados para realização da análise. Também foram adotados indicadores socioeconomicos e demográficos, pois é importante considerar, segundo revisão bibliográfica, que algumas diferenças nos padrões de deslocamento podem ser causadas por esses indicadores.

A definição da hipótese central apoiou-se na premissa que o ambiente construído exerce influência sobre o comportamento de viagens, pois a morfologia e a forma de ocupação de uma cidade podem dificultar ou facilitar a adoção de diversos modais.

Na pesquisa, com relação à análise do espaço urbano, será dado destaque aos plinths - espaços de transição entre a rua e o lote - buscando confirmar a hipótese central de que estes espaços tem maior influência nos deslocamentos dos pedestres quando comparados com outras variaveis. Através da revisão bibliográfica foi verificado que esta variável não é comumente adota nos estudo desta linha de pesquisa. Especialistas como Jan Gehl e Jeff Speck dissertam acerca da importância de desenhar esses lugares e trabalhar a cidade ao nível dos olhos para a vitalidade dos espaços públicos.

Tomando como premissa a influência do ambiente urbano nos deslocamentos, a pesquisa deseja buscar compreender as lógicas por trás das preferências de rotas realizadas ao caminhar e as percepções dos pedestres quanto aos seus deslocamentos.

Reconhece-se a ampla quantidade de indicadores e fatores que pretende-se utilizar na análise, cujo recorte espacial compreende o bairro da Torre. Esse fator, junto a questão temporal da realização da pesquisa no período de um ano suscita a possibilidade de definir recortes dentro do bairro. Esses recortes devem incluir áreas representativas da dinâmica do dia-a-dia do bairro.

A pesquisa também pretende contribuir, em termos práticos, com a proposição de diretrizes de intervenção, no âmbito físico e organizacional/gestão, que visam a melhoria da caminhabilidade no bairro da Torre. Devido ao nível de integração global do bairro com a cidade, é possivel antever que algumas destas diretrizes extrapolarão a escala do bairro e vão impactar também na escala da cidade.

Trabalhos como este devem ser continuados e aprimorados. É sugerida a continuidade na exploração dos aspectos relativos as tipologias edilicias e os plinths, tendo em consideração os resultados obtidos em pesquisa anteriormente realizadas, com destaque para os encontrados por Netto et al. (2012), e os resultados que se espera obter com a conclusão desta pesquisa, confirmando a hipótese central.

Ainda, recomenda-se que trabalhos como este sejam realizados analisando outros bairros, seja de João Pessoa ou outra cidade brasileira. Os resultados obtidos devem ser abertamente divulgados e levados aos setores responsaveis da gestão pública, de modo a contribuir com as avaliações realizadas por estes setore e auxiliar na definição e implantação de políticas de planejamento e mobilidade urbana. 


\section{BIBLIOGRAFIA}

AMÂNCIO, M. A. y DA PENHA SANCHES, S. (2008). A forma urbana e as viagens a pé - estudo de caso em uma cidade brasileira de porte médio. Acta Scientiarum. Technology, 30 (2).

ANDRADE, P. A. F. de. (2007). Metamorfose dos centros urbanos: uma análise das transformações na centralidade de João Pessoa - PB, 1970 - 2006. João Pessoa: Universidade Federal da Paraíba - UFPB.

ANDRADE, P. A. F., RIBEIRO, E. L. y SILVEIRA, J. A. R. (2009). Centralidade urbana na cidade de João Pessoa - PB: uma análise dos usos comerciais e de serviços entre o centro tradicional e o centro seletivo 1970/2006. Arquitextos, Vitruvius (São Paulo): 9(106.06).

ARUP. (2016) Cities alive: towards a walking world. Londres: Arup.

BARROS, A. P. B. G. et al. (2013) Impacto do desenho da malha viária na mobilidade urbana sustentável. V Congresso Luso-Brasileiro para o Planejamento Urbano, Regional, Integrado e Sustentável, Brasília. «< https://www.researchgate.net/profile/Ana_Paula_Barros/>>

BRADSHAW, C. (1993) A rating system for neighbourhood walkability: towards na agenda for local heroes. Proceedings of the International Pedestrian Conference, Ottawa, Canada.

BRASIL.
<http://www.ibge.gov.br/home/estatistica/populacao/censo2010/default.shtm>> (Consulta 30/08/2016).

BRASIL. Ministério das Cidades. Conselho Nacional de Trânsito. Departamento Nacional de Trânsito. (2016). Relatório Estatístico de Frota de veículos. Brasília: DENATRAN.

CAO, X., HANDY, S. y MOKHTARIAN, P. (2006). The influence of the built environment and residential selfseletion on pedestrian behavior. Transportation Press.

CERVERO, R., DUNCAN, M. (2003). Walking, bicycling and urban landscapes: evidence from San Francisco Bay Area. American Journal of Public Health, 93(9), 1478-1483.

CERVERO, R., KOCKELMAN, K. (1997). Travel demand and the 3 Ds: density, diversity and design. Transportation Research Part D, 2(4), 199-219: Oxford.

CERVERO, R., RADISCH, C. (1996). Travel choices in pedestrian versus automobile oriented neighborhoods. Transport Policy, 3(3), 127-141.

COUTINHO, M. A. F. (2004). Evolução urbana e qualidade de vida: o caso da Avenida Epitácio Pessoa. João Pessoa: Universidade Federal da Paraíba, UFPB.

EWING, R. H. (1999) Pedestrian and transit-friendly design: a primer for smart growth. Washington, DC: Smart growth network.

EWING, R., CERVERO, R. (2001). Travel and the built environment: a synthesis. Transportation research record: Journal of the American planning association, (1780), 87-114.

(2012). Travel and the built environment: a meta-analysis. Journal of the American planning association, 76(3), 265-294.

FAJARDO, W. (2015). Andabilidade. Rio de Janeiro: Jornal O Globo. « http://oglobo.globo.com/opiniao/andabilidade-15138730>> (Consulta 27/07/2015)

FERNANDES, K. D. L. M.; MAIA, M. L. A. y FERRAZ, C. (2008). Forma urbana e deslocamentos pendulares: uma análise dos bairros de Casa Caiada e Jardim Brasil em Olinda - PE. XXII ANPET Congresso de pesquisa e ensino em transportes. Fortaleza: Panorama nacional de pesquisa e ensino em transporte, (1), 763-775. 
FRANK, L. D. y PIVO, G. (1995). Impacts of mixed use and density on utilization of three models of travel: single-occupant vehicle, transit and walking. Transportation Research Record, (1466), 44-52.

FRUIN, J. J. (1971). Pedestrian planning and design. New York: Metropolitan Association of Urban Designers and Environmental Planners.

GEHL, J. (2013). Cidades para pessoas. São Paulo: Editora Perspectiva.

GHIDINI, R Jr. (2011). A caminhabilidade: medida urbana sustentável. Revista dos Transportes Públicos, (127), 21-33.

HAMMOND, D. (2005). Residential location and commute mode choice. Cardiff: University of Wales.

ITDP. (2018). Índice de Caminhabilidade: Ferramenta, versão 2.0. Rio de Janeiro: ITDP Brasil.

KRAMBECK, H. V. (2006). The global walkability index. Massachusetts: Massachusetts Institute of Technology.

LARRANAGA, A. M. L. (2012) Estrutura urbana e viagens a pé. Porto Alegre: Universidade Federal do Rio Grande do Sul.

LARRAÑAGA, A.M., TEM CATEN, C. S. y CYBIS, H. B. B. (2009). Relação entre estrutura urbana e padrão de viagens a pé. XXIII Congresso de ensino e pesquisa em transportes. Anais do congresso.

LUCENA, J. G. de. (2016). Índice de caminhabilidade - região central de João Pessoa. João Pessoa: Universidade Federal da Paraíba - UFPB. <<https://issuu.com/jessicalucena/docs/indice_caminhabilidade〉> (Consulta 11/06/2017).

MACHRY, S. y MONTEIRO, C. (2014). Andabilidade urbana - Metodologia de avaliação e de gestão da qualidade urbana. Cóloquio Ibero-Americano - Paisagem Cultural, Patrimônio e Projeto, Belo Horizonte.

NETTO, V. M., VARGAS, J. C. C. y SABOYA, R. T. (2012). (Buscando) Os efeitos sociais da morfologia arquitetônica. urbe. Revista Brasileira de Gestão Urbana [online]. 4(2), 261-282.

(2015). A arquitetura importa para a cidade? $<<$ https://caosplanejado.com/a-arquitetura-importa-paraa-cidade/>> (Consulta 26/11/2017).

PASSOS, L. A. et al. (2012). Processo de expansão versus sustentabilidade urbana: reflexão sobre as alternativas de deslocamento na cidade de João Pessoa, $P B$. urbe. Revista Brasileira de Gestão Urbana (Brazilian Journal of Urban Management), 4(1), 47-59.

RODRIGUES, A. R. P. et al. (2013). Indicadores do desenho urbano e sua relação com a propensão a caminhada. Rio de Janeiro, 1, 1-27.

SALES, A. L. P. (2009). O centro principal de João Pessoa: espacialidade, historicidade e centralidades. João Pessoa: UFPB/CCEN.

SILVA, C. H. M. et al . (2012). Avaliação das condições de caminhabilidade nas áreas centrais de Salvador e Aracaju, Brasil. XV CIU - Congresso Iberoamericano de Urbanismo, Medellin, Colômbia. Medellin: Editorial Universidad Pontificia Bolivariana.

SILVEIRA, J. A. R., LAPA, T. A. y RIBEIRO, E. L. (2007). Percursos e processo de evolução urbana: uma análise dos deslocamentos e da segregação na cidade. Arquitextos, Vitruvius (São Paulo) 8(90.04).

SPECK, Jeff. (2016) Cidade caminhável. $1^{a}$ edição. São Paulo: Perspectiva.

STIPO. (2015). A cidade ao nível dos olhos: lições para os plinths. Editado por Hans Karssenberg et al. Porto Alegre: EDIPUCRS,. 
VARGAS, J. C. B. (2015). Forma urbana e rotas de pedestres. Porto Alegre: Universidade Federal do Rio Grande do Sul.

VILLAÇA, F. (2001). Espaço intra-urbano no Brasil. São Paulo: Studio Nobel/FAPESP/Lincoln Institute.

ZEGRAS, P. C. (2004). Influence of land use on travel behavior in Santiago Chile. Transportation Research Record. (1898), 175-182. 